\title{
Problems of ineffective modernization at industrial enterprises and ways of their solution
}

\author{
Dmitry Kiselev ${ }^{1, *}$, Yuri Popov ${ }^{1}$, and Olga Kanygina ${ }^{1}$ \\ ${ }^{1}$ Volgograd State Technical University (VSTU), Russia
}

\begin{abstract}
The article considers the reasons of inefficient modernization of industrial enterprises. The above statistics confirm the need for a qualitative transformation of technological processes and approaches in the organization and management of production enterprises. Primarily this is due to technical and moral condition of fixed assets and the level of innovation in enterprises. The authors identified several major causes of the problem (inefficient) industrial modernization, which also explains the weak and the dynamics of modernization processes in Russia. The problem is due to how ineffective the actions of the heads of enterprises and factors of external environment. The authors see the solution of the mentioned problems in several directions related to the activities of state bodies and improvement actions of the management of enterprises.
\end{abstract}

\section{Introduction}

For many years in Russia at different levels raise issues related to a significant lag in the technological level of the production base of domestic industrial enterprises, not only from world-class companies, but also from the requirements of the current demand in the markets of the country. The need for radical change repeatedly discussed at various levels of government and the scientific community, and, as a rule, in the process of reindustrialization of the industry or the modernization of some of its segments.

In most cases, the products produced by domestic enterprises, is uncompetitive in many respects, including fixed - price and quality, and their relationship. Also note that the domestic enterprises give little importance to systems adapted promotion and service products, accounting for a considerable share in a competitive advantage in industrial markets. This makes many domestic manufacturers to occupy a worthy place in the markets of not only international level, but also across the country.

The ongoing modernization of industrial enterprises is often ineffective, because not achieved the intended system purpose and/or upgrade costs are more predictable because of flaws in the planned activities, which lowers the expected financial result.

\section{The analysis of statistical data}

In general, the activity of industrial enterprises is characterized by low levels of revenue and profit, which are much lower than expected and unit cost often exceeds all reasonable limits. Official statistics [1] based on cost of production and selling products per 1 rub. of output in the Russian Federation as a whole senses the presence of profits of industrial enterprises, but there is a negative trend in 2015, while for some types of activities the same, or close to 1 rub., or exceeds it, i.e. enterprises operating at a loss.

Table 1. Dynamics of production costs and selling products.

\begin{tabular}{|c|c|c|}
\hline $\begin{array}{c}\text { The cost of production } \\
\text { and selling products } \\
\text { per } 1 \text { ruble of the } \\
\text { manufactured } \\
\text { products, (rub) }\end{array}$ & $\mathbf{2 0 1 5}$ & $\mathbf{2 0 1 6}$ \\
\hline machine tools & 0,935 & 0,899 \\
\hline $\begin{array}{c}\text { lifting and handling } \\
\text { equipment }\end{array}$ & 0,943 & 0,911 \\
\hline $\begin{array}{c}\text { woodworking } \\
\text { machinery }\end{array}$ & 0,938 & 1,023 \\
\hline $\begin{array}{c}\text { machines and } \\
\text { equipment for mining } \\
\text { and construction }\end{array}$ & 0,996 & 1,065 \\
\hline $\begin{array}{c}\text { forging equipment } \\
\text { machines for animal } \\
\text { husbandry }\end{array}$ & 1,096 & 0,732 \\
\hline $\begin{array}{c}\text { other machines, not } \\
\text { included in other } \\
\text { groupings }\end{array}$ & 1,031 & 1,118 \\
\hline
\end{tabular}

The volume of shipped goods of own production in the manufacturing sector has a constant growth trend over the past 7 years the increase amounted to $236 \%$

\footnotetext{
* Corresponding author: kiselevde7@yandex.ru
} 
(2016 - 33 898,1 billion rubles - in 2009. - 14 351,9 billion rubles), including: manufacture of machinery and equipment $182 \%$; the manufacture of electrical and optical equipment $-251 \%$, production of vehicles and equipment $280 \%$. However, if we turn to the production volumes of industrial products (machines, equipment, vehicles, and equipment) in real terms, in the period 2012-2014. (official data on 2015 and 2016 missing) recorded a decrease of production volumes.

Modernization of production in the first place should be directed to the fixed assets of enterprises. In the domestic industry condition of capital assets requires the acceleration of the pace of modernization, since statistics [1] shows that the average age of machinery and equipment is $11.2 \mathrm{~g}$., and in manufacturing of $12.1 \mathrm{~g}$. the Degree of deterioration reaches of $47.1 \%$, and the proportion of completely worn-out Fund - of $15.8 \%$, including machinery and equipment of $24.5 \%$ in the manufacturing sector, $15 \%$ and $20.5 \%$, respectively.

In addition to technical state of assets of enterprises, the importance of the modernization is orientation to the innovative development. However, only a minority of businesses seeking to introduce technological innovations in production. In 2015, they accounted for $8.3 \%$ of all organizations that have an innovative activity. And this despite the fact that the cost of innovation has increased from 2010 in 3 times (from 400 803,8 million to 1200363,8 million) [1].

If we consider the costs of domestic enterprises for R\&d in \% of GDP, the rate is 1.24 percent, while in the leading countries it is equal to $2,5 \%-4,5 \%$, and in the "second tier" - 1,5\% - 2,5\%, while the absolute size of r\&d spending in Russia is significantly lower.

Table 2. Structure of R\&d funding in the world [2].

\begin{tabular}{|c|c|c|c|c|c|}
\hline Country & \multirow{2}{*}{$\begin{array}{c}\text { R\&d } \\
\text { expenses, } \\
\text { \$ million. } \\
\text { USA }\end{array}$} & \multicolumn{4}{|c|}{$\begin{array}{c}\text { The share of sectors in funding } \\
\text { R\&d costs, \% }\end{array}$} \\
\cline { 3 - 6 } & ess & State & $\begin{array}{c}\text { Foreign } \\
\text { investor } \\
\text { s }\end{array}$ & $\begin{array}{c}\text { Other } \\
\text { source } \\
\text { s }\end{array}$ \\
\hline USA & 456977 & 60,9 & 27,7 & 4,5 & 6,9 \\
\hline China & 333521,6 & 74,6 & 21,1 & 0,9 & 3,4 \\
\hline Japan & 162347,2 & 75,5 & 17,3 & 0,5 & 6,7 \\
\hline $\begin{array}{c}\text { South } \\
\text { Korea }\end{array}$ & 68051,5 & 75,7 & 23,8 & 0,3 & 1,1 \\
\hline France & 57986,8 & 55,4 & 35,0 & 7,6 & 2,0 \\
\hline UK & 41743,4 & 46,6 & 27,0 & 20,7 & 5,7 \\
\hline Russia & 36614 & 28,2 & 67,6 & 3,0 & 1,2 \\
\hline Poland & 8114 & 30,0 & 61,0 & 5,6 & 3,4 \\
\hline
\end{tabular}

We add that the world economic forum brought the indicator "the ability of companies to borrow and adapt technologies", according to which Russia is on the 41 place among 133 countries. This suggests that Russian enterprises for various reasons do not tend to invest not only in the development and introduction of own technologies and innovations, but is even difficult to borrow advanced technology from their Western colleagues. In the end we have a system, "focused on imitation, and not to create radical innovations and new technologies" [3]. All this points to the weakness of governance in domestic enterprises, which are in most cases unable to become leaders in their industry, and just trying to follow the technological leaders of the West. Details of the reasons for the decline in investment flows to the science highlighted in [4], including: lack of demand from the business sector on the results of scientific activities, the lack of near term returns from basic research in the field of science, devoted to the economic problems, the lack of clear financial guidelines, etc.

It is obvious that in order to claim the role of leader, there must be sufficient volume of all types of resources including financial and intellectual. Here we must again regret to say that, on the one hand, or financial-credit institution, nor the state contributes to obtaining cheap long-term funds on a substantial development and/or modernization of production facilities and other enterprises are experiencing an acute shortage of personnel that could ensure the leading position of domestic producers and developers.

Often businesses are investing heavily in the modernization of production and management systems, however, do not get the expected results. The question arises, how justified is in these cases, the ongoing modernization involving replacement or improvement of fixed assets and production technologies, retrain staff and change suppliers with the introduction of modern principles and approaches in the organization and management of production. All of this requires substantial financial investments, some of which are at the expense of public funds, often not giving the expected return. In the opinion of the authors, there are several most important reasons why most of the modernization programmers do not give the expected effect.

\section{Problems of ineffective modernization}

The invalidity of the modernization programs. "The immediate motive of modernization is a mismatch between resources and the level of skills of the enterprise" [5]. Modernization, as any action within the enterprise cannot be undertaken for its own sake, and must rely on a well-designed purpose that provides an understanding of what she is. This understanding is based on data about what characteristics will have the market in which the company operates. The availability of these data is ensured by several factors.

First, it is a fully developed and multidimensional statistical data, which should be easy access. Unlike Western developed countries, the available statistical database in Russia more than scarce. The average entrepreneur who does not have access to the resources of government, practically deprived of the opportunity to assess the state of the market in which it operates, especially at the regional level. Accordingly, there is no opportunity to assess the degree of saturation of a particular market niches and customer satisfaction.

Second, is the formation of forecasts of development of the market situation. The lack of access to statistical data deprives managers of the ability to generate objective forecasts using statistical models. In addition to quantitative projections, there is a scarcity of qualitative 
projections generated by the experts. If you still have the opportunity to find a quality expert forecasts at the Federal level, the forecasts of the regional level is practically absent. It simultaneously points to the lack of appropriate specialists (experts), and lack of demand for their services.

Thirdly, it is marketing research, which unlike even the best statistical data show characteristics of the buyers, the nuances of their behavior and their problems and intentions. Analysis of the market of such services in the city of Volgograd showed that the demand for marketing research is tends to zero. On the one hand, this is due to the fact that business leaders do not realize the entire benefit of marketing research, and on the other, what do marketing companies do not have enough specialists who could show the benefits of such research through qualitative work.

The weakness of the above factors determines the fact that the leaders of organizations and entrepreneurs are unable to develop a full and reasonable strategy that would ensure their success in the target market. Lack of strategy leads to lack of comprehension when making decisions about upgrading, because executives do not understand why it is performed, and what results they can expect. As a consequence, current actions, and related financial investments ineffective. This problem is especially evident in small and medium-sized enterprises, which usually do not have the capacity to have on staff specialists in strategic analysis and strategy development for financial reasons.

The lack of planning or weak. Observations show that the organization of small and medium format in the management process almost does not involve planning. This is due to such factors as burdensome expenses on the collection and analysis of information; the difficulty of developing internal standards in planning; the downplaying of the role of planning, the desire to work intuitively, not knowing the types and kinds of planning.

Large companies, given the scale of their activities, are forced to carry out planning, including strategic, tactical or limited. We should note that the quality of the development of plans varies significantly: some companies develop complete plans, others take their planning to the formal procedures and often limited to a plan to sell [6].

One of the issues is inefficient modernization of large enterprises, with a network of offices and branches is inefficient budgeting system, aimed at the development of the budget in a timely manner, often leading to irrational allocation of resources across time and across types of work in economic activity and in the decrease of efficiency of expenses on modernization of production facilities.

Insufficient level of qualification of the staff. Speaking of qualifications, here it is necessary to involve all categories of employees.

First, it is the managers who in most cases do not possess sufficient knowledge and skills in the development of the strategy. In the vast majority of cases the documents in the title which is the word "strategy", they are not, it is at best a long-term plan. A big role plays the effectiveness of the management responsible for the strategic and tactical planning and management. In relation to the ongoing enterprise modernization requires particular attention to innovative management, involving design, forecasting, effective decision-making.

Secondly, it engineering staff, which, based on the latest scientific discoveries and development needs by relating their own ideas and projects with forecasted characteristics of the demand, to form a product, the characteristics of which are demanded by target markets in the foreseeable future, with reference to and which needs to be modernized. Again, by analyzing the activity of the domestic enterprises, we can see that in many cases new products is not a good enough copy of what has already been developed by foreign companies. In those cases when it is possible to create world-class products, it still is not always in demand. Moreover, such products are often not reached the stage of mass production. Real gains have mainly to say in cases where the products are manufactured under the order. In other words, domestic engineers, as a rule, it does not show the ability to anticipate the future; to go for bold decisions; to create products that can become a reference point for foreign businesses to find creative solutions to resolve certain problems, etc. To some extent, the assistance in that they could assist marketing experts, studying the problem from consumers, but in the vast majority of cases, this category of workers, the management of the enterprise driving all marketing activities in the area of product promotion, which reduces the professional level of marketers.

Thirdly, it is the direct perpetrators - production workers, which to some extent depends on the quality of products. Despite the fact that the primary responsibility for this lies with the leadership, a lack of skilled workers, low production and other factors do not allow to produce competitive products.

The lack of long-term development goals. The goal of modern managers is primarily in the area of minimizing costs to maximize profit in a short period, all efforts are focused on using the market to achieve shortterm goals. Often the management is following the path of least resistance, reducing first costs for personnel and materials. Enterprise development, including modernization, is not correlated with the specified target setting. The modernization includes the transformation of fixed assets, of the logistics system of the enterprise processes enterprise management requires a strategic and long-term decisions and longer payback period.

The lack of a productive mechanism for assessing the appropriateness and effectiveness of public investment. We have already mentioned that a large part of innovation is the initiative, and therefore with the support of the state. It is obvious that the government allocates adequate financial resources. However, as practice shows, there are no clearly proven and effective mechanisms to assess the appropriateness of investing public funds so that they bring good returns at least in the long term. Thus, we can figuratively say that the state plays in a losing of the lottery, which is unacceptable, given the sources of state revenues and existing obligations. 
Obviously, there must be some structure that will carry out a comprehensive market assessment of the proposed projects. It should be recognized that such organizations exist, for example "Agency for strategic initiatives". But, just look at the website of the Agency to understand that it from the entire set required for such structure functions performs only one - the transfer of public money into projects. Indeed, this organization does not help either to develop efficient projects, nor to evaluate their market or social desirability, for which he was subjected to sharp criticism by the Russian President at the end of 2016.

The sanctions restrictions. The complicated geopolitical situation around Russia, has led to significant restrictions in the supply of new technologies and equipment to domestic enterprises and finished industrial products from abroad and made it difficult for exports. And those businesses that are leaders in technological development, and those who try to use the strategy of following the leaders (imitation), currently face important constraints in the implementation of the modernization process. Difficult situation and fragmentation of relations in science and industry do not allow to compensate for these limitations through the manufacture and supply of domestic technologies and equipment. It should be noted that the issue of revitalization of the industrial enterprises is largely a matter of the time required for design and development (modernization) of production capacities, setting up a system of promotion and service of products, the required return on investment. The current economic and geopolitical situation increases uncertainty and leads to significant risks for investors.

\section{Direction in solving the problems identified}

1. Strengthening the activities of the state in creating a favorable information environment for conducting business. This includes not only better quality of the statistical base available to entrepreneurs and business leaders, but also the encouragement, including financial aspects, creation of research institutes, centers and units as on a commercial basis, and research-based organizations. Currently there is an acute shortage of professionals who can effectively collect information, process it and generate a reasonably accurate projections and estimates. Therefore, at the initial stage, emphasis should be placed on the training of such experts

2. To create the conditions necessary qualification and quality management leaders of the organization. At present one should speak not just about the absence of market relations in Russia, but also about the growing monopolization of markets, both at Federal and regional levels. You should make every effort to promote competition, which will create a greater number of businesses. Those that will be more competitive, will become the centers of attraction of investments; qualified personnel; the attention of buyers, suppliers and marketing intermediaries, etc. The leaders of the companies that have to deal with the outflow of all these resources will be forced to look for ways to improve the skills and quality of management. In this situation, significant importance will be the adaptation of training programs in various training centers of the needs of the market.

3. Reorientation ineffective reform of higher education by absorption (dissolution) of educational institutions to increase the effectiveness of their training [7]. In this case, you must change the parameters for assessing the effectiveness of training. The main criterion for evaluating the educational institution should be the quality of training of graduates, its demand in the labourmarket, and in an additional - additional criteria, such as number of scientific papers, often not reflecting the level of the teacher and his work; the amount earned by teachers, financial resources, etc. Accordingly, should change and qualifications of the teaching staff, which appropriately should be subject to direct (appraisal fee, etc.) and indirect (students ' knowledge) assessment. Negative testing experience of students in the framework of the procedures of attestation of Universities showed that one should look for other ways of inspection. It should be particularly noted that the growth of these requirements is meaningless without a real increase in the level of motivation and stimulation of workers of educational institutions.

4. Integration of industry and science. The experience of world leaders, proves the impossibility of sustainable and dynamic development of the economy and the competitiveness of enterprises without deep integration of industry and science. The success of individual domestic enterprises do not give opportunities to talk about systemic change in the whole industry. The responsibility for such integration falls not so much on the state, which must actively influence both sides of the process as on the businesses themselves that need to pay more attention to the qualification of its employees and cooperation with scientific and research organizations.

5. The main impetus in the implementation of the previous two paragraphs can specify the state. It is appropriate to talk about the partnership of business, educational and research organizations and the state, which can be seen in the various system interactions $[8$, 9, 10 11]: clusters, public-private partnerships or concessions, priority development areas, etc. we emphasize that the role of the state should not be passive, i.e. reduced to some guarantees, promises, preferences, etc., but at the same time and should not violate the laws of the market economy, to encourage competition. You need to create a stable and favorable institutional environment for business, ready to observe the laws and to bear their share of social responsibility, which is necessary to ensure strict observance of laws after thorough revision to ensure realism and to corruption [12].

6. The creation of new effective structures and improvement of existing organizations that can provide real assistance to entrepreneurs and businesses in the development of various projects with elements of innovation and modernization and to conduct a comprehensive evaluation of the proposed projects in terms of the viability and profitability based on global- 
level indicators. Observations show that, in the majority of cases the leaders are in dire need of not only effective consulting support, but also teaching business and management in market conditions. Almost always mismanagement and the collapse of the organizations (except illegal action) are the result of ignorance of basic management theories and techniques. Here the great role of the organization in the likeness of the chambers of Commerce, business incubators, etc.

7. Systematizing and improving the effectiveness of corporate planning, including strategic, tactical and operational cycles, but with a primary focus on the development of strategic plans. While the main focus should be on strategic and marketing studies and market forecasting. This will generate a more informed and therefore effective strategies and, thereby, to increase the level of decisions, including in the field of modernization of production, which will be more focused - with a focus on specific investment opportunities in the market.

\section{Conclusion}

The state of the economy and industry in Russia continues to be at a high enough level. Despite the breakthroughs in a very narrow spheres of activity, the competitiveness of most enterprises and their products is low. Assessing the reasons for this situation, many note the high level of physical and moral depreciation of fixed assets of domestic enterprises and the substantial technological gap due to insufficient investment in science, both at the country level and at the level of individual enterprises.

At the same time, there are many examples where significant investments in innovative activity, inextricably linked with the modernization of production, did not bring the results expected. Products updated its productive and technological base, were often as not in demand as the products made on the basis of the old production technologies.

The reasons for this situation due to deficiencies in the activities of the various stakeholders in the economic and managerial relations. Businesses that are upgrading, are not sufficient to base their decisions on statistical data, expert forecasts, and marketing research. Insufficient level of qualification of managers and employees does not allow to formulate long-term and strategic goals, and develop plans and innovative products designed to meet the needs of the market. The state by providing funding for the most significant innovative and modernization projects, is weak control over the reasonability of their usage, which leads to low efficiency of such investment. The weak interaction of scientific and educational institutions and the industrial complex to reduce the possibilities for a qualitative transformation of production processes and marketing.

The most important areas of focus to remedy this situation, according to the authors, should be considered a significant improvement in the information base for making informed decisions when upgrading. Increasing the level of training of managerial and engineering personnel of enterprises should be a priority in solving the considered problems. It is necessary to improve the activities of educational institutions for the training of personnel with adequate qualifications and research organizations to enhance research and the integration of their work with industrial enterprises. Appropriate and more active state involvement in significant projects to build conditions for business development through comprehensive support and forming partnerships.

\section{References}

1. Federal State Statistics Service: http://www.gks.ru

2. National Science Board. 2016. Arlington, VA: National Science Foundation Science and Engineering Indicators 2016 (NSB-2016-1), 4/45-46 (2016).

3. Ministry of Economic Development of the Russian Federation, The strategy of innovative development of the Russian Federation for the period till 2020, 16 (2011)

4. A.A. Tarasyev, I.A. Krivenko, M.S. Pecherkina, T.O. Kashina, Economy of Region, 12(1), 303-314 (2016)

5. G.B. Kleiner, Economy of Region, 13(1), 13-24 (2017)

6. D. Kiselev, Y. Popov, O Kanygina, Globalization and Its Socio-Economic Consequences, 16th International Scientific Conference, II, 884-891 (2016)

7. Ye.V. Balatsky, Journal of the new economic association, 4(24), 111-140 (2014)

8. 8 S. Zemtsov, V. Barinova, A. Pankratov, E. Kutsenko, Foresight and STI Governance, 10(3), 34-52 (2016)

9. V. Abashkin, A. Boyarov, E. Kutsenko, ForesightRussia, 6(3), 16-27 (2012)

10. O.A. Romanova, Economy of Region, 1, $43-56$ (2014)

11. N.V. Kashina, Economy of Region, 12(2), 569-585 (2016)

12. G.A. Yavlinsky, Journal of the new economic association, 2(26), 173-178 (2015) 